\title{
Improving mental health in families with autistic children: benefits of using video feedback in parent counselling sessions offered alongside music therapy
}

\begin{abstract}
BACKGROUND
This paper explores benefits of parent counselling offered alongside music therapy with children with autism spectrum disorders (ASD). Research studies have shown that the stress levels of primary caregivers of children with ASD are not only higher than in the general population but also higher than in parents of children with other developmental disabilities. It is therefore recommended that music therapists working with children with ASD also engage and support their parents.
\end{abstract}

PARTICIPANTS AND PROCEDURE

In the international randomised controlled trial TIME-A, which investigates the effects of music therapy on the social communicative skills of autistic children, participating families are offered three parent counselling sessions. For this paper, 68 counselling sessions with 25 families were evaluated; 14 sessions were transcribed and subjected to a content analysis. Case examples illustrate the impact of concomitant parent counselling sessions on the families.

\section{RESULTS}

The analysis generated emerging themes that were grouped into two categories: 1) Non-music therapy spe- cific themes, and 2) Music therapy specific themes. The first category comprised four sub-groups: Exchange of information, Experiences with professionals/friends/society, Worries about the future, Personal/matrimonial problems. Music therapy specific themes were subdivided into the following groups: Working in a partnership, Empowering parents, Celebrating strengths, Rejoicing in child's enjoyment. Challenges caused by the dual roles of music therapist and parent counsellor were outweighed by the benefits. In addition to the therapeutic effect of counselling, video material from the music therapy sessions helped carers to see their children's strengths, to gain new ideas, and to develop a more positive outlook.

\section{CONCLUSIONS}

The findings support the provision of parent counselling sessions alongside music therapy for children with ASD. This study highlights that extending the role of the music therapist and using video feedback offers encouraging possibilities to further support the wellbeing of the whole family.

\section{KEY WORDS}

music therapy; autism; parent counselling; video feedback; emotional wellbeing

ORganization - 1: Anglia Ruskin University, Music Therapy Centre, Cambridge, United Kingdom · 2: Cambridgeshire Music, Huntingdon, United Kingdom

AUthors' Contributions - A: Study design - B: Data collection - C: Statistical analysis - D: Data interpretation .

E: Manuscript preparation · F: Literature search · G: Funds collection

CORRESPONDIng AUthor - Laura K. Blauth, Anglia Ruskin University, Music Therapy Centre, Young Street, Cambridge, CB1 2LZ, United Kingdom, e-mail: lakab@gmx.de

TO CITE THIS ARTICLE - Blauth, L. K. (2017). Improving mental health in families with autistic children: benefits of using video feedback in parent counselling sessions offered alongside music therapy. Health Psychology Report, 5(2), 138-150. doi: https://doi.org/10.5114/hpr.2017.63558 


\section{BACKGROUND: TIME-A STUDY}

All the parent counselling sessions described in this paper have been conducted for the international research study TIME-A (Trial of Improvisational Music therapy's Effectiveness for children with Autism). TIME-A aims to determine whether music therapy improves the social communicative skills of young children with autism spectrum disorders (Geretsegger, Holck, \& Gold, 2012). It is the largest randomised controlled trial on non-pharmacological treatment for autism so far, with 364 children from nine countries (Australia, Austria, Brazil, Israel, Italy, Korea, Norway, UK, and USA) enrolled in the study. All children included have a diagnosis of autism spectrum disorder (ASD) and were aged between 4 years and 6 years 11 months at the time of their randomisation. Participants were randomly assigned to one of three conditions:

- high-intensity music therapy: individual music therapy three times a week for five months, and three parent counselling sessions as a standard care condition;

- low-intensity music therapy: individual music therapy once a week for five months, and three parent counselling sessions as a standard care condition;

- standard care: three parent counselling sessions.

The primary outcome measure is the Autism Diagnostic Observation Schedule (ADOS), which is administered by a blinded assessor. In addition, parents were asked to complete the Social Responsiveness Scale (SRS). Both standardised scales were collected at baseline, after 2 months, after 5 months and after 12 months.

All families in the study, regardless of their child's allocation, have been offered three parent counselling sessions, conducted by a clinical psychologist or the child's music therapist, which lasted approximately 60 minutes each. The TIME-A study protocol describes the content and purpose of the parent counselling sessions as follows:

"Counselling sessions will comprise supporting conversations with a focus on current concerns, problems, and difficulties arising from the child's diagnosis, behaviour, and development over time as well as providing information about ASD, child development, and social communication relevant to the families' everyday life situations" (Geretsegger et al., 2012, p. 4).

Some notes regarding the terminology are necessary at this point. Several children in the study cohort live with foster carers. In this paper, the terms parent or carer will be used interchangeably and always refer to the primary caregiver. The standard care condition in the TIME-A study protocol is termed counselling. I will therefore adopt the same term in this paper. However, our team in the UK discussed alternative descriptions such as advisory sessions or parent meetings. As I have no formal training in counselling, the service we offer must be distinguished from the therapy provided by a specialist counsellor.

\section{RATIONALE FOR PARENT COUNSELLING SESSIONS}

Autism spectrum disorder is a neurodevelopmental disability that affects approximately $1 \%$ of the population (Baird et al., 2006; Brugha et al., 2012). The core symptoms are persistent deficits in social communication and social interaction as well as restricted, repetitive patterns of behaviour (American Psychiatric Association, 2013). The condition ASD is likely to have an impact on the whole family and not only the child diagnosed (Greef \& Van der Walt, 2010). Strained family relationships, disturbed family routines, and grieving for the loss of the expected healthy child are typical sources of parental stress when caring for an autistic child. Families affected by ASD often experience social isolation as a result of the characteristic features of the condition. Studies have shown that caregivers of children with ASD suffer more often from depression and anxiety than the general population (Khanna et al., 2011), with consequences for their physical health (Lovell, Moss, \& Wetherell, 2012). They also experience markedly higher levels of stress and aggravation than parents of children with other developmental disabilities (Dabrowska \& Pisula, 2010; Estes et al., 2009; Schieve, Blumberg, Rice, Visser, \& Boyle, 2007).

A literature review by Boyd (2002) concluded that "low levels of social support were the most powerful predictors of depression and anxiety in mothers" (p. 209) of children with ASD. Social and parental support was also mentioned in a study by Greef and Van der Walt (2010) as one main aspect that contributed to family resilience and functioning. Further positive factors reported by parents were professional help and advice, treatment programmes, and knowledge of autism. These results indicate that necessary intervention for the child diagnosed with ASD should be complemented by support and psychological help for their carers and families.

\section{DEFINING MY APPROACH}

Previous work experience had convinced me that family-centred approaches have very positive effects. I was therefore excited to be able to work as a parent counsellor for the research trial. At the same time, however, I was aware that meeting with and counselling parents requires "skills that are complementary to, but different from, clinical music therapy"
Benefits of video feedback in parent counselling 
(Grogan \& Knak, 2002, p. 210). In order to prepare for my new role, I consulted literature concerned with music therapy interventions for children and their parents. Beyond that, psychology literature pertinent to my new responsibilities helped me to define my approach.

\section{PARENTS IN MUSIC THERAPY}

Laura K. Blauth

The parent-child relationship has been attended to by numerous music therapists. Reasons for that are, among others, the striking similarities between early parent-infant communication and musical interactions (Malloch, 1999; Papousek, 1996). Both are non-verbal, intuitive, spontaneous, and playful (Oldfield \& Bunce, 2001). The music-like interactions between child and parent further the important processes of bonding and attuning to each other. Accordingly, music seems to be a suitable medium to possibly (re)experience this early developmental relating. It is thus not surprising that an increasing number of music therapists provide music therapy for children and their carers.

Music therapy groups are offered for several parent-child dyads that need support because of disadvantageous circumstances or a diagnosis such as global developmental delay or ASD (Bull, 2008; Loth, 2008; Oldfield \& Bunce, 2001). The presence of other families that might experience similar problems can help parents to feel more relaxed, to socialise, and to benefit from peer support. For other dyads, individual music therapy might be more useful. Work in this area has also been documented and reflected on (Drake, 2011; Flower, 2008; Oldfield, 2008). Children are often referred with a carer when they are very young, physically fragile, or when a disorder such as ASD has interfered with attachment processes. The therapy is usually concerned with the individual needs of both child and parent as well as with their relationship issues.

Two recent studies by Thompson, McFerran, and Gold (2014), and by Schwartzberg and Silverman (2016) investigated parents' perception of music therapy with autistic children. Thompson et al. (2014) concluded that family-centred music therapy strengthens the parent-child relationship. Parents perceived an improvement in the quality of their child's social interactions as well as in their own abilities to relate positively to the child. Schwartzberg and Silverman (2016) analysed semi-structured interviews with parents and discovered recurrent themes, such as "the collaborative approach benefits all aspects of treatment and promotes rapport and alliance", and "parents independently implement techniques used in music therapy in other settings". Both studies support previous findings highlighting the importance of sharing ideas with parents that they can explore outside the sessions (Oldfield, 2011; Loth, 2008).
The above-mentioned literature reflects on music therapy with children and their parents. Carers are present and take an active part in the music therapy sessions. Conversations between the music therapist and parent are usually short, as they happen during or after the session while the child plays. In child psychotherapy, the model of simultaneous treatment (Chazan, 2003), during which the child and the parent are seen separately by the same therapist, is well established. However, literature in music therapy that explores simultaneous treatment of the child and parent remains scarce. Grogan and Knak (2002) propose the idea of a "discussion group for parents in parallel to a children's group" (p. 211), and suggest that this may be run by another professional. The music therapist Tali Gottfried has directed both music therapy and parent counselling sessions for the TIME-A site in Israel. She investigated the effects of her specific approach music-oriented parent counselling (MOPC), and reported improvements in parental stress level, quality of life perception, and the use of music in everyday life (Gottfried, 2016). Music-oriented parent counselling comprises supportive conversations and music therapy-like techniques (e.g. musical improvisation) but does not, unlike my approach, include video feedback as an essential element. I am not aware of any model outside the TIME-A context that offers separate parent counselling sessions alongside music therapy for the child.

\section{COUNSELLING SKILLS}

In order to acquire more specific ideas about counselling I consulted literature in psychology. Especially the person-centred approach developed by Carl Rogers $(1951,1961)$ was influential and inspirational. He believed that the therapist had to hold certain attitudes towards the client in order to help and promote change. The first attitude is called unconditional positive regard, which implies showing respect and warmth to the client and being absolutely non-judgemental. Further attitudes are termed empathy and congruence. Empathy describes the attempt to see the world from the client's perspective and to communicate this understanding. Being congruent means being genuine, authentic and transparent. As these personal attitudes determine the quality of the relationship, they seem paramount to me and provided helpful guidance for the work.

Davis (1993) and Pelham and Stacey (1999) outlined basic skills that complement these attitudes. A distinction must be made between formal counselling and the use of counselling skills which can be employed by anyone facilitating communication. Davis delineates them as attending, active listening, prompting, demonstrating empathy, and basic 
exploration. A similar set of fundamental counselling skills is described by Pelham and Stacey (1999): "Just" being there, facilitating the person to tell his or her story, attending to repeating patterns of behaviour, and use of the therapeutic frame. Being able to hold a silence, awareness of transference and counter-transference processes, as well as the ability to hold and contain the therapeutic relationship constitute essential principles.

\section{VIDEO FEEDBACK}

From my work experience in child and family psychiatry I was familiar with the use of video feedback, as it is applied regularly by different team members in the unit (Holmes, Oldfield, \& Polichroniadis, 2011). The music therapist Oldfield has written extensively about her use of video recordings with parents (Holmes et al., 2011; Oldfield, 2006). A meta-analysis of 29 studies concluded that interventions using video feedback have a positive effect on families with young children (Fukkink, 2008). Parenting behaviour, attitude of parents, and, consequently, the development of the child all showed significant improvements. A recent randomised controlled trial (Poslawsky et al., 2015) demonstrated that the video-feedback intervention to promote positive parenting adapted to autism (VIPP-AUTI) reduced parental intrusiveness and increased feelings of self-efficacy.

For my role as a parent counsellor in TIME-A, my procedure had to be different from these methods in the sense that I was not primarily utilising feedback of parent interactions but offering video feedback of their child's music therapy to parents. Nevertheless, effective techniques could be learned, and the research findings supported the belief that using video feedback in an intervention like parent counselling sessions could be highly beneficial.

\section{SUMMARY}

The above-cited literature and research influenced my approach for the parent counselling sessions. Working collaboratively with carers, sharing ideas with them, and valuing their expertise and opinion are understood to be necessary and beneficial. Simultaneous treatment of children with ASD and their parents, as requested by the TIME-A research protocol, provided a suitable treatment model. My relationship with carers was characterised by holding a positive, non-judgemental, empathic and genuine attitude towards them. An essential technique used in the counselling sessions was showing video excerpts that demonstrated the child's strengths and successful interactions.

\section{PARTICIPANTS AND PROCEDURE}

\section{PARTICIPANTS}

I have worked as a music therapist and parent counsellor for one site of the trial in the UK where I was responsible for 26 children. They were recruited in three schools and had a mean age of 5 years 6 months at randomisation. In this cohort, 21 children attended special schools and five children attended a mainstream school. Four participants were female. The majority of children at this site were assessed with ADOS Module 1, receiving a mean summary score of $M=18.22(S D=4.25)$. Three children were evaluated using ADOS Module 2 with a mean summary score of $M=11.33$ $(S D=4.71)$. In the SRS rated by parents, 23 children obtained a $T$-score of $\geq 76$ and thus fell into the category 'Severe range'. Two children received a $T$-score corresponding to the 'Moderate range'. The SRS of one child could not be scored as more than 16 item responses were missing (see Constantino \& Gruber, 2005). In this cohort, 14 children were randomly assigned to music therapy, of whom 8 children were allocated to the high-intensity treatment. Participation in the study seemed highly acceptable and feasible. All families with eligible children that were approached agreed to take part in the trial. One family dropped out after the child was randomised to the standard care condition.

Apart from improvisational music therapy sessions I also conducted the parent counselling sessions for all 25 families who engaged in the project. In six cases children lived with a single parent, and four children lived with foster parents. Carers of 20 children attended all three sessions offered to them. Acceptance was very good, with 68 out of 75 possible sessions being delivered. An even higher attendance of 41 out of 42 possible sessions could be observed in the subgroup of families whose children received concurrent music therapy intervention. The family members present at these sessions varied. Most commonly, the female primary carer attended the meeting on her own (43 sessions), and significantly less often the father on his own (6 sessions). In several sessions both carers attended together or other family members such as grandparents or siblings were present (19 sessions).

\section{METHODS}

Most of the parent counselling sessions (64 sessions) were videotaped. In the four other sessions carers preferred not to be recorded. After each appointment, detailed session notes were prepared and significant events, emergent topics and parent behaviours documented. In addition, I recorded
Benefits of video feedback in parent counselling 
my emotional responses to each session in order to separate a more factual description from my interpretation. The notes were extended with quotes and further information after having watched all 64 video tapes once. Video rather than audio recording provided further insight into parents' emotional responses such as facial expressions and body language. In addition, video examples from the parent counselling sessions proved to be powerful material that I was able to show, with carers' consent, to school staff and professionals when advocating for music therapy as well as for parent support.

As I am specifically interested in the benefits of using video feedback in sessions offered alongside music therapy, I transcribed 14 sessions conducted with carers of the children who were randomised to music therapy. Because of time constraints I chose to transcribe only one, namely the second, of the three sessions each family was offered. The first sessions were often centred on providing general information about music therapy, as well as learning about the background and current situation of the child and family. Video feedback did not play a major part as the first counselling sessions coincided with the beginning of the music therapy treatment. Even though the third meetings usually encompassed extensive video feedback, questions about future treatment possibilities and recommendations proved to be constitutive parts of all final meetings. The second parent counselling sessions were scheduled two months after the beginning of the music therapy intervention and therefore provided ample opportunities to include video feedback. The relationship between carers and counsellor was already established, and thoughts about ending did not yet dominate the conversation. Although I initially intended to exclusively use the 14 transcribed sessions for a content analysis, reviewing all tapes convinced me that the 54 non-transcribed sessions captured additional important information. That is why the extensive notes made after having watched video recordings of all sessions were included to some extent in the analysis.

Examining the content of the parent counselling sessions, comments from carers could be grouped together which allowed for emergent themes to be detected. The interpretation of data was based on the six phases of thematic analysis by Braun and Clarke (2006), which are 1) familiarising yourself with the data, 2) generating initial codes, 3) searching for themes, 4) reviewing themes, 5) defining and naming themes, and 6) producing the report. I organised the themes under two headings: 1) Non-music therapy specific themes, and 2) Music therapy specific themes. Both categories comprise several sub-categories which are presented and discussed in the following section.

\section{EMERGENT THEMES}

Non-music therapy specific

Non-music therapy specific themes were collated from all 25 families attending the counselling sessions, regardless of the treatment group their child was allocated to. Four sub-categories could be identified: (1a) Exchange of information; (1b) Experiences with professionals/friends/society; (1c) Worries about the future; (1d) Personal/matrimonial problems.

(1a) Exchange of information. Almost all the contact with carers started with talking about the child's background and current presentation. Parents seemed keen to tell me about the early years, the medical history and their first concerns. It felt important that they could share this information with someone who showed interest and had time to listen to their narrative without diversion. We discussed recent progress and changes, the child's behaviour at school and at home, and likes or dislikes. Parents often gave a detailed description of their child's characteristics, such as "He has completely no awareness of danger whatsoever", or "He is such an affectionate and loving boy". When invited, most parents talked happily about the child's skills, their favourite activities, and cherished moments. However, six of the 25 families struggled to think of any positives and needed lots of encouragement and support to remember characteristics or behaviours of the child they were proud of.

The exchange of information also comprised knowledge about ASD. Several parents used part of the sessions to ask questions about the condition, such as "How many children with ASD will learn to speak?". Carers also tried to acquire more information about the other children I was seeing to assess the severity of their own child. They asked for example "When you compare him to the others, is he doing well?". Very practical questions concerning behaviour management or advice regarding visual aids were also common. All the families were interested in learning more about music therapy and the research study.

(1b) Experiences with professionals/friends/ society. A striking element of many sessions was the amount of anger and disappointment carers voiced. This frustration often concerned the contact with professionals, including paediatricians or therapists, as well as school staff. Parents talked about long waiting lists, rushed appointments and insufficient information. The most stressful aspect, however, seems to be that professionals usually focus on difficulties and impairments of the child. One carer communicated his discontent with this deficit-oriented approach very clearly:

Try to understand what are his strengths which absolutely nobody--, which is missing. So everybody 
is talking about his weakness all the time and saying he's weak. Yes, we--, that's an accepted thing but not talking about his strengths and saying, okay these are his strengths, let's work on his strengths and make sure he makes something out of it.

Further disappointments seem to be frequently caused by experiences with neighbours or friends. One mother was desperate because her child's noisiness upset the neighbours to the point that she was not greeted any more. Other parents mentioned that friends seemed unable to cope with the special needs of the child, which resulted in a compromised social life. Carers often tried to find an explanation themselves, making comments such as "I had to cancel too often. I think they've given up”. One parent reflected on an unpleasant encounter she had made when trying to visit a public place with her child, and used the session to make sense of this incidence:

Yeah, and somebody came and said, "Oh, there has been a complaint made against you because of your child's noise and this and that", and I--, I got upset and I was like, "Oh, he is autistic and he doesn't really cope", and they were like, "Oh, right". When you look at [child's name] he doesn't look disabled, does he, well he's not, he's not. I don't think he is disabled but he doesn't look like there is anything wrong with him. So I think people just assume he is being naughty rather than thinking, "Oh, maybe he's got a little bit of extra needs".

An important aspect of the counselling sessions seemed to be that they provided a safe space for carers to talk about these difficult experiences. They were listened to without being judged, and thus were able to express feelings of disappointment, sadness and anger:

And I got very, very mad and I said to her "It's people like you that make me sick because you are just looking at him like--". There is no understanding, there is no sort of sympathy towards him in that specific minute. So I was just like, "Come on", and I was calming down. 'Cause it is hard as a mother, you know what it's going to be like in the future.

(1c) Worries about the future. A common theme in many conversations with carers was uncertainty about the future. Parents worried about the changes that will occur when their children grow older and develop sexual desires or more physical strength:

So many times when he has hurt me and I think, "Oh my God, he is only five. What is he gonna be like when he is twelve, fifteen?".

One family had a clear idea of the abilities and needs of their daughter. They communicated the concern that her strengths would not be fostered enough for her to succeed and overcome her difficulties in the future:

We feel that she could grow up and get degrees from universities and things like that but not have the confidence to take them out and doing things with them or be able to express herself properly. So she might as well not have them, do you know what I mean. We think her confidence, her being able to express herself and be social, is much more important than her results from academic things.

Thinking about the future proved to be distressing for most families. The uncertainty seemed to be an essential aspect. Even though every parent has to bear a certain amount of not knowing, more questions must remain unanswered for carers of children with autism: How much independence will their child be able to gain? Will their child develop speech? Will their child be able to work, socialise, be happy?

We really hope he gets better and better and better, and we don't have to take care of him the rest of our lives but... That's the biggest concern we have. We want him to live independently, find a job, bigger or smaller. Right now I am worried sick.

(1d) Personal/matrimonial problems. The counselling sessions offered carers a space to talk about their own problems. I explained that they could use their time in any way they wanted. All carers talked about worries caused specifically by the autism diagnosis of their child as described above. In addition, 10 families used the space to talk about personal problems traditionally associated with counselling. These themes comprised matrimonial problems, low mood, stressful financial situation, bereavement, and traumatic experiences. One carer talked with me about the recent loss of a family member, while another carer worked through some difficult aspects of his history. The stress of insufficient housing or financial means was discussed:

They are cutting our foster allowances. [...] We think they are doing things they shouldn't be doing. It's a minefield, so we just got to work through it. Anyhow, bet we'll be living in a tent soon [laughs]. So we got all that worry going on.

Three parents confided their own struggles with mental health to me. Matrimonial problems were brought to the sessions by four families. Even though it seemed helpful that these families were provided with a safe space to talk about their difficulties, it became apparent that the offered service was not sufficient to work together towards positive changes. I had neither received professional counselling training, nor had the possibility to deliver more than three sessions for each family. This meant that problems could only be attended to in a limited way. I reminded carers repeatedly of our framework and referred them to other services if necessary. However, for some families it seemed beneficial to just voice their problems to a non-judgemental professional.

\section{Music therapy specific themes}

The above-mentioned non-music therapy specific themes emerged in counselling sessions with all 25 families. With the 14 families whose children were
Benefits of video feedback in parent counselling 
randomised to the music therapy treatment, music therapy specific themes consistently occurred in the counselling sessions. These themes could be grouped into the following categories: (2a) Working in a partnership; (2b) Empowering parents; (2c) Celebrating strengths; (2d) Rejoicing in child's enjoyment. Quotes from different carers as well as two case vignettes illustrate the four areas.

(2a) Working in a partnership. The importance of parental involvement has been widely recognised, and a desirable form of the relationship between therapist and parent is often described as a partnership (Horvat \& O’Neill, 2008; Oldfield, 2006, 2011; Schwartzberg \& Silverman, 2016). The sessions with carers provided opportunities to discuss the suitability of music therapy aims for the child and the progress towards them. Parents could be included in this constant evaluation process, and their views were taken into account. It became apparent how much parents valued being heard and seeing their aspirations informing the music therapy. This promoted a trusting relationship and emphasised that we were working in a partnership rather than disconnected from each other.

The following case vignette gives an example of how working in a partnership with the carer was achieved during the counselling sessions. It seemed important that a feeling of trust and togetherness was created in the first session and then strengthened in the following sessions. In order to illustrate this process I use transcribed excerpts from all three sessions in this case vignette.

Case vignette. In the first counselling session with the mother of four year-old Leo ${ }^{1}$, we discussed the aims for Leo's music therapy.

(P - Parent, T - Therapist, (Yeah) - Interjection from other speaker)

T: I wrote down the aims that I set so far, and I thought maybe we can think about them together (Yeah), because I've only known him for two weeks (Okay). So after the first sessions with him I thought that these are some things I would like to focus on with him.

I explain the first aims to her and give some examples of musical activities that might help us achieve these aims.

P: That's everything that he needs as well. So that's really good.

T: Good, yeah, and then the last two are just--, I want to provide a space for him where he can be creative, where he can be playful, where he can just enjoy playing with things, exploring, um, have a good experience really, just have something to boost his self-esteem and his confidence.

P: Ooh, yeah, no I'm really happy with all of them. They are very good.

T: Good, okay, great. I always like to double-check with the parents because sometimes--, I mean, you know your child so much better.
P: Yeah, but to be fair, all these things that he lacks is everything that you've put on there, to be fair, I would say that.

When I asked Leo's mother in the first session about her aims and wishes for her son she told me that she hoped for him to develop speech. At the time I started seeing Leo, he was the only non-verbal child in his classroom. It was obvious that his mother found that very difficult. We therefore agreed that working on Leo's vocalisations and speech would be made a priority in our music therapy sessions. Accordingly, I selected excerpts for the video feedback in the second and third counselling sessions that showed Leo being engaged in vocal interactions.

\section{Session 1}

$\mathrm{P}$ : And I think someone like Leo is a very good example because he doesn't even have single words, you know, and if he does start saying single words, that's a big deal. Especially for us in our family, a very big deal.

\section{Session 2}

We are watching a video clip of Leo singing a song with me:

P: Oh my God! [laughs] Ooh! Ooh! That's amazing! (Yes!) I can't believe he was doing--, I get, what--, he wasn't saying it like how you were saying it, but, it was like he was saying it--, I can't explain it. You could tell that's what he was trying to sing.

$\mathrm{T}$ : Yes, he was using the right vowels, he was using the right melody--

$$
\text { P: Yeah... }
$$

\section{Session 3}

T: How are you at the moment?

P: I'm good. I'm really disappointed that he's got last, he's had his last like music therapy, 'cause I really feel like it's really, really working for him. I don't want him to go backwards from not having it. He, actually, he sings so much! It's unbelievable. Even this morning he woke up at half six in the morning and he just sits there and sings. And he says all of it and it's just like, my baby can talk! He talks through that and that's amazing!

(2b) Empowering parents. Even though carers obviously enjoyed watching their child succeeding in the music therapy sessions, this also provoked difficult feelings at times. Some parents felt insecure, started thinking that the therapist had all the expertise, and questioned their own skills. I sometimes sensed envy related to the therapist's musical skills as well as to the ability to connect with the child. This dynamic has also been reported by therapists working with carers in the music therapy session (Levinge, 2011; Oldfield, 2006). Primary caregivers of autistic children often experienced adversities that may have threatened their self-image as competent 
and 'good-enough' parents. Even though increased knowledge about the aetiology of autism has helped many carers of children with ASD to perceive themselves not as the cause of the diagnosis, some parents may still self-blame for their child's difficulties (Schwartzberg \& Silverman, 2016). It was pointed out that these unresolved issues can lead to a parent feeling resentful towards a therapist who is establishing connections with their child (Oldfield, 2006). As a counsellor working with both the parent and the child, it was crucial to be aware of these dynamics, and to carefully avoid rivalry and competition with the carer. The following example shows how this was addressed in the sessions:

P: He enjoyed that! I just can't work out--, when he seems to be in these videos he seems really contained. I--, I--, it's really good. But for me he'd probably be lying around the floor. That's what I'm saying, that's really good! To me that's like, "Wow, that's my son doing that". That's really good! I'm really impressed.

$\mathrm{T}$ : Yeah, but I mean it all comes from somewhere. He must--, I mean, the interactions that he has learned from you, that's all showing in here.

P: Yeah...

$\mathrm{T}$ : I can tell that he lives in a very good environment for him to thrive.

Another effective way to empower parents was to think together about possible implementations of music activities into their daily routines. Skill sharing helped carers to gain feelings of self-efficacy and self-esteem.

(2c) Celebrating strengths. Video feedback often helped carers to see and appreciate their child's strengths. I deliberately chose excerpts that revealed positive interactions and developments. For some of these families music therapy was one of the few or even the first space where attention was drawn to the child's abilities. The setting allowed children to succeed and to enjoy music making, interacting and being playful. Many parents were surprised or moved by what their child was able to do during music therapy:

Oh, and this is her idea? If anyone said to me, "Is [child's name] creative?", I would say "No". Do you know what I mean? Because she is very not creative in other ways. She feels so comfortable, doesn't she, in the music. Situations to be able to, like, be more of what she is.

Carers often put huge effort into arranging transport, time and someone to look after siblings in order to attend the counselling sessions and particularly, as many emphasised, to see the progress of their child in music therapy. This indicates how much enjoyment and hope they gained from the video feedback. We often used the space to celebrate the child's achievements together. Having worked with a child intensely for a considerable amount of time enabled me to recognise and appreciate little steps towards more independence and growth. Carers seemed to be glad that they could share their enjoyment of these developments with me.

P: Wow, [laughs] it's amazing, hmm, enjoying it!

T: When I watch back at the videos I always think, like, "Wow, that's really, really amazing how he progressed!"

P: Yes, my God! Yes, good. He is relaxed, copying, waiting, everything. It's good.

T: And I think you can--, you can tell that music really has a good effect on him. Music helps him to wait, music helps him to communicate.

P: Communicate, yeah. To feel, maybe, happy. Sometimes before, maybe sometimes, he was very sad, or sometimes uncomfortable, but music helps him to feel happy. Yeah, it's good.

(2d) Rejoicing in child's enjoyment. The preceding comment from a mother also reveals another important aspect: All parents clearly rejoiced in their children's delight. Music therapists who have gathered parents' perceptions of being in the session with their child concluded that rejoicing in their child's enjoyment is a common feeling (Drake, 2008; Loth, 2008; Oldfield, 2011). However, when children start school they usually receive therapies without their parents. Using video feedback in the counselling sessions allowed carers to still witness the joy of their child in music therapy. As Fingerman, Cheng, Birditt, and Zarit (2011) stated that parents are "only as happy as the least happy child", this delight must not be undervalued when considering carers' mental wellbeing. One of the benefits of video feedback is that the material can be re-watched several times. Handing the videos to parents at the end of the therapeutic relationship allows them to keep a memory of these happy moments and revisit them in more difficult times.

P: When we finish--, when you've finished with him, do we--, are we able to have any of this?

T: Yes, I will make a DVD with all these excerpts.

P: Really? Oh, wow!

$\mathrm{T}$ : Yes, I have them all here together, so you can also have them.

P: Oh, brilliant.

T: It's nice to have a memory, isn't it.

P: It's nice for us because [voice breaks] it's nice to see that he's doing so well in something, where he's actually smiling and enjoying it for a period of time [starts crying].

Case vignette. The following case vignette further illustrates the above-mentioned themes. All excerpts were taken from the second parent counselling session with the carers of Christopher, an only child who was randomised to high-intensity music therapy. Christopher was non-verbal and nearly seven years old when I started seeing him. Both parents attended all three sessions.
Benefits of video feedback in parent counselling 


\section{Empowering parents (2b)}

$\mathrm{P}$ : We've been doing more of what you suggested (Mm-hm). Um, so I-- I--, we did before but we are making more time to, um, use the instruments that he's got at home and to, to mimic the sounds that he is making (Yeah). That's the one thing I took away from our last conversation (Mm-hm). So I've been focusing more on that. And it seems to be, um, he seems to enjoy it. And it does seem to create moments where we are in the moment together (Yeah). So that's really nice.

T: So something for you to enjoy as well, a positive time.

$\mathrm{P}$ : Yeah! Because it is sometimes difficult, a lot of times difficult, to create situations that we share together.

$$
* * *
$$

P: But now he initiates it, and that's really great! It's all that, both in the making of sounds, sharing sounds together, which is communication, but also the dancing, that he initiates it. He wants me to be part of that. We did a lot of that before but I kind of invaded his world. Now I sort of feel like he's enjoying it more, and more asking for it, and asking for it as something to do together as opposed to just putting up with me (Yeah, great). And what you were saying, that's what rang a bell in my head. Sometimes, you know, when you can sort of take each other's hands and spin round and spin back. We've been able to do that together. He would never be able to do that before. Before I was feeling like I was invading his world, you know.

$\mathrm{T}$ : It's nicer for you as well to have the feeling that--. Like you say, invading his world is not really a thing you want to do.

P: No exactly, exactly. Thank you, I just wanted to say.

\section{Celebrating strengths (2c)}

P: Thank you very much for showing us. It's so lovely to see Christopher really--, the difference even in what you've showed us last time, so interesting! And the difference that we can see on here (Mm-hm). His involvement and his interaction, it's all there. It's great to see, isn't it. It's really great to see! And it's also--, it's nice to take these times out. Because, when you asked us when we first arrived about the changes--. And there is so many challenges (Mm-hm) every day that you can--, we can sometimes get lost in the challenges of every day. And we try always to take moments out, to enjoy those moments of positivity and creativeness and progress that he is having, getting really to know Christopher, Christopher interacting with us. But you can sometimes feel overwhelmed with the day-to-day things.

$\mathrm{T}$ : Because it is very tiring.

$\mathrm{P}:$ It is.
T: And then finding the energy to celebrate the good things.

P: Yes.

T: It's not always easy.

P: Sometimes the first things that come to mind are the things we keep looking for as opposed to things that we are enjoying.

P: And I think with his sounds--, I think I'm also more in tune with his sounds now (Mm-hm). Because he's been making so many sounds all of his life but being more in tune about those sounds, in tune with him (Mm-hm), listening for his patterns in his sounds and how they are changing $(\mathrm{Mm}-\mathrm{hm})$. I think I see more than I've seen before.

$\mathrm{T}$ : Mm-hm, yeah. I think he has a real--, a really clear own voice $(\mathrm{Mm}-\mathrm{hm})$, and the vocal sounds he is making, they have a distinct character that's Christopher.

P: Yes, yes. I think I appreciate that much more $(\mathrm{Mm}-\mathrm{hm})$. And I think I appreciate it more, so I'm more attuned to him (Mm-hm). But also he is trying more out, there is different patterns, there is different sounds that sound much more like--, 'cause he can sometimes make sounds which I think is his way of actually dampening down things around him (Yeah). But there are times where I've seen you--, where there is different sounds he is making, and different rhythms that he is making which is, as you say, feel more like Christopher's own voice. So that's brilliant... It's nice... It's wonderful.

\section{Rejoicing in child's enjoyment (2d)}

After having watched video excerpt:

T: So I think that's a big change.

P: Isn't it! Yeah!

$\mathrm{T}$ : He is coming to sit with me and really sharing the instrument, sharing the song. And--

$P$ : And his attention in watching you while being able to sit and watch and allowing you to play and be part of that. Really good concentration, really good looking, wasn't it (Yeah). Really good looking! And then to explore, and some really nice movements and sounds.

T: Yeah, the nice thing is his creative exploring (Yes). He isn't only copying what I did, strumming, but he goes along the strings, he plucks them (Yeah). And he--, his excitement--

P: I think that smile at the end! He was really, really enjoying that. Yeah, that's lovely.

\section{DISCUSSION}

\section{CHALLENGES}

Taking up the dual role of music therapist and parent counsellor for the TIME-A study has posed several 
challenges regarding relationships, space and time. Relationships were affected on various levels between all three agents: child, carer and therapist. The carer's construction of the child was sometimes challenged by the video feedback. Some children were very aware that their parents came into school to see their music therapist, which could cause feelings of envy or anxiety regarding their relationships with both adults. In the counselling sessions, the therapist built a rapport with the parent. Grogan and Knak (2002, p. 211) have described how this connection might affect the course of therapy with the child:

"We have found that the greater the contact with parents, the more the relationship between therapists and parents becomes a part of the work with the children".

Intertwined relationships are not necessarily a disadvantage and might indeed further therapeutic processes on different levels. However, it is essential to become aware of these interconnections and think about them carefully. Regular supervision proved to be of utmost importance.

The counselling sessions had to take place in the child's school, which caused issues regarding the space. The school is not a neutral place for many parents. Positive or negative experiences, memories and associations might be attached to the school. This will always have an influence on the emotional constitution of carers when they attend the counselling session. Another challenge proved to be the availability and consistency of a room. Schools are busy places where space is often short and flexible adaptation necessary. In one school, I had to change the venue for the counselling sessions which caused feelings of puzzlement in some carers. An important issue regarding space was ensuring confidentiality. Teachers saw parents coming in for their sessions and sometimes approached me afterwards to discuss their own experiences with the parent. I had to be clear that I needed to preserve confidentiality while keeping a positive relationship with the teacher.

Time constraints had big effects on the practicability of fulfilling the dual roles. Counselling sessions had to be scheduled during school hours in order to have access to the space. This meant that some carers needed to take time off work. The duration and number of sessions was determined by the research protocol, with little leeway for clinical judgement. This did not always suit the needs of the individual parent. The greatest challenge was the time-consuming preparation needed for the work as a parent counsellor. Video feedback was an essential element of my approach, and I quickly became convinced of the gained benefits. However, in order to use video feedback effectively, many hours of editing were needed. When thinking of the feasibility of this model for general practice it is important to consider the additional hours of work caused by it. Providing parent counselling sessions with video feedback alongside music therapy for children is only possible if enough time is granted for thorough preparation. This preparation cannot be accomplished during unpaid hours in the evening if the result is to be satisfactory, meaningful and beneficial for carers.

\section{BENEFITS}

While it is important to reflect on the challenges, the benefits of parent counselling sessions, and especially of using video feedback, seem to outweigh the difficulties. Parents often asked for detailed information about the trial and commented that this helped them to feel "more in charge". Parents were valued as partners both in research and in clinical practice. The concurrent sessions provided me as a music therapist with plenty of invaluable information about the children I was working with. Carers' comments on video material were often insightful and expanded my understanding of the child's behaviour and the meaning of our interactions. Their contribution enhanced the music therapy sessions.

Some of the families involved in this project were described by teachers as "hard to reach". The fact that they came to the school on three different occasions opened pathways for staff members to interact with parents. The counselling sessions contributed to a strengthened relationship between parents and schools.

"This relationship [between parents and schools] is essential for the successful education of all children, but it is vital for children on the autism spectrum, who often require a wide range of special services to meet their needs" (Brooks \& Goldstein, 2012, p. 233).

Increased parental engagement in the school was evident in several carers who started advocating for more music therapy, and who met teachers after counselling sessions to discuss their child's development. Accordingly, feedback from staff has been very positive. Teachers benefited from the edited video material, which could be used, with the consent of carers, to demonstrate positive child behaviour or a successful technique. Staff members from one school were inspired after these presentations to implement more music in their daily school routines. The counselling sessions meant that I was on site more often and available for feedback or advice. A music group, conducted by two enthusiastic teaching assistants, is still taking place regularly in this school.

Most importantly, the carers themselves have expressed their appreciation of this model. The high attendance, especially in the group allocated to music therapy, indicates that the session format was appropriate. It seems justified to assume that the counsel-
Benefits of video feedback in parent counselling 
ling sessions fulfilled a need otherwise unmet by service providers. Carers used the sessions in a variety of ways to ask questions, to talk about their child's development, the impact of ASD, and other worries. Video feedback focused on the child's strengths and provided opportunities to celebrate progress together. Using video feedback as a means of engaging parents as partners, empowering them, and sharing positive moments seemed to be a successful and highly appreciated method:

It's so lovely to see [child's name] doing so much. It really is, it really is. Thank you very much, thank you very much both for working with him and being able to show us, 'cause that's--, that's such a lovely positive thing. It's really nice to see!

\section{SUMMARY AND FUTURE OUTLOOK}

A content analysis of counselling sessions with parents of children with ASD generated emerging themes that could be grouped into two categories: 1) Non-music therapy specific themes, and 2) Music therapy specific themes. The first category comprised four sub-groups: Exchange of information; Experiences with professionals/friends/society; Worries about the future; Personal/matrimonial problems. Music therapy specific themes were subdivided into the following groups: Working in a partnership; Empowering parents; Celebrating strengths; Rejoicing in child's enjoyment.

Challenges regarding relationships, space and time were caused by the dual roles of music therapist and parent counsellor. Benefits included enhanced music therapy sessions, increased parental engagement, and provision of a safe space for parents to discuss worries. Moreover, video material from the music therapy sessions helped carers to see their children's strengths, to gain new ideas, and to develop a more positive outlook. This study highlights that extending the role of the music therapist and using video feedback offers encouraging possibilities to further support the wellbeing of the whole family. As a result, Cambridgeshire Music in the UK has started a pilot project to investigate the practicability and impact of regular counselling sessions for parents of children who receive music therapy in schools. Further research in this area is needed to develop an applicable model for general practice. My future research plans to examine the effects of music therapy and concurrent parent counselling sessions on the resilience of young children with ASD and their families.

\section{ENDNOTE}

1 To preseive confidentiality, names of all clients have been changed.

\section{REFERENCES}

American Psychiatric Association. (2013). Diagnostic and statistical manual of mental disorders ( $5^{\text {th }} \mathrm{ed}$.). Arlington, VA: American Psychiatric Publishing.

Baird, G., Simonoff, E., Pickles, A., Chandler, S., Loucas, T., Meldrum, D., \& Charman, T. (2006). Prevalence of disorders of the autism spectrum in a population cohort of children in South Thames: the Special Needs and Autism Project (SNAP). Lancet, 368, 210-215. doi: 10.1016/S0140-6736(06)69041-7

Boyd, B. A. (2002). Examining the relationship between stress and lack of social support in mothers of children with autism. Focus on Autism and other Developmental Disabilities, 17, 209-215. doi: 10.1177/10883576020170040301

Braun, V., \& Clarke, V. (2006). Using thematic analysis in psychology. Qualitative Research in Psychology, 3, 77-101.

Brooks, R., \& Goldstein, S. (2012). Raising resilient children with autism spectrum disorders. Strategies for maximizing their strengths, coping with adversity, and developing a social mindset. New York: McGraw-Hill.

Brugha, T., Cooper, S. A., McManus, S., Purdon, S., Scott, F. J., Spiers, N., \& Tyrer, F. (2012). Estimating the prevalence of autism spectrum conditions in adults: extending the 2007 Adult Psychiatric Morbidity Survey. Leeds: The NHS Information Centre.

Bull, R. (2008). Autism and the family: group music therapy with mothers and children. In A. Oldfield \& C. Flower (eds.), Music therapy with children and their families (pp. 71-87). London: Jessica Kingsley Publishers.

Chazan, S. E. (2003). Simultaneous treatment of parent and child. London, UK: Jessica Kingsley Publishers.

Constantino, J. N., \& Gruber, C. P. (2005). Social Responsiveness Scale: Manual. Los Angeles, CA: Western Psychological Services.

Dabrowska, A., \& Pisula, E. (2010). Parenting stress and coping styles in mothers and fathers of preschool children with autism and Down syndrome. Journal of Intellectual Disability Research, 54, 266280. doi: 10.1111/j.1365-2788.2010.01258.x

Davis, H. (1993). Counselling parents of children with chronic illness or disability. Leicester: BPS Books.

Drake, T. (2008). Back to basics. Community-based music therapy for vulnerable young children and their parents. In A. Oldfield \& C. Flower (eds.), Music therapy with children and their families (pp. 37-51). Jessica Kingsley Publishers: London and Philadelphia.

Drake, T. (2011). Becoming in tune: The use of music therapy to assist the developing bond between traumatized children and their new adoptive parents. In J. Edwards (ed.), Music therapy and parent-infant bonding (pp. 22-41). Oxford: Oxford University Press. 
Estes, A., Munson, J., Dawson, G., Koehler, E., Zhou, X. H., \& Abbott, R. (2009). Parenting stress and psychological functioning among mothers of preschool children with autism and developmental delay. Autism, 13, 375-387. doi: 10.1177/1362361309105658

Fingerman, K. L., Cheng, Y., Birditt, K., \& Zarit, S. (2012). Only as happy as the least happy child: multiple grown children's problems and successes and middle-aged parents' well-being. The Journals of Gerontology Series B: Psychological Sciences and Social Sciences, 67B, 184-193. doi: 10.1093/ geronb/gbr086

Flower, C. (2008). Living with dying: reflections on family music therapy with children near the end of life. In A. Oldfield \& C. Flower (eds.), Music therapy with children and their families (pp. 177-189). London: Jessica Kingsley Publishers.

Fukkink, R. G. (2008). Video feedback in widescreen: A meta-analysis of family programs. Clinical Psychology Review, 28, 904-916. doi: 10.1016/j. cpr.2008.01.003

Geretsegger, M., Holck, U., \& Gold, C. (2012). Randomised controlled trial of music therapy's effectiveness for children with autism spectrum disorders (TIME-A): study protocol. BMC Pediatrics, 12, 2. doi: 10.1186/1471-2431-12-2

Gottfried, T. (2016). Creating bridges: Music-Oriented Counseling for Parents of children with Autism Spectrum Disorder (ASD). Doctoral Study. Unpublished. Derived from: http://www.mt-phd.aau.dk/ organisation/current/tali_gottfried/

Greeff, A. P., \& Van der Walt, K. (2010). Resilience in families with an autistic child. Education and Training in Autism and Developmental Disabilities, 45, 347-355.

Grogan, K., \& Knak, D. (2002). A children's group. An exploration of the framework necessary for therapeutic work. In A. Davies \& E. Richards (eds.), Music therapy and group work. Sound company (pp. 202-215). Jessica Kingsley Publishers: London and Philadelphia.

Holmes, J., Oldfield, A., \& Polichroniadis (eds.). (2011). Creating change for complex children and their families. A multi-disciplinary approach to multi-family work. London: Jessica Kingsley.

Horvat, J., \& O'Neill, N. (2008). 'Who is the Therapy For?': Involving a parent or carer in their child's music therapy. In A. Oldfield \& C. Flower (eds.), Music therapy with children and their families (pp. 89-102). London: Jessica Kingsley Publishers.

Khanna, R., Madhavan, S. S., Smith, M. J., Patrick, J. H., Tworek, C., \& Becker-Cottrill, B. (2011). Assessment of health-related quality of life among primary caregivers of children with autism spectrum disorders. Journal of Autism and Developmental Disorders, 41, 1214-1227. doi: 10.1007/s10803-0101140-6
Levinge, A. (2011). 'The first time ever I saw your face...': Music therapy for depressed mothers and their infants. In J. Edwards (ed.), Music therapy and parent-infant bonding (pp. 42-57). Oxford: Oxford University Press.

Loth, H. (2008). Music therapy groups for families with a learning-disabled toddler: bridging some gaps. In A. Oldfield \& C. Flower (eds.), Music therapy with children and their families (pp. 53-69). London: Jessica Kingsley Publishers.

Lovell, B., Moss, M., \& Wetherell, M. (2012). The psychosocial, endocrine and immune consequences of caring for a child with autism or ADHD. Psychoneuroendocrinology, 37, 534-542. doi: 10.1016/j. psyneuen.2011.08.003

Malloch, S. (1999). Mothers and infants and communicative musicality. Musicae Scientiae, 3 (Suppl 1), 29-57. doi: 10.1177/10298649000030S104

Oldfield, A. (2006). Interactive music therapy - a positive approach: music therapy at a child development centre. London: Jessica Kingsley Publishers.

Oldfield, A. (2008). Working in partnership and supporting parents: music therapy for pre-school children and their parents at a child development centre. In A. Oldfield \& C. Flower (eds.), Music therapy with children and their families (pp. 1936). London: Jessica Kingsley.

Oldfield, A. (2011). Parents' perceptions of being in music therapy sessions with their children: What is our role as music therapists with parents? In J. Edwards (ed.), Music Therapy and Parent-Infant Bonding (pp. 58-72). Oxford: Oxford University Press.

Oldfield, A., \& Bunce, L. (2001). 'Mummy can play too...' Short-term music therapy with mothers and young children. British Journal of Music Therapy, 15, 27-36.

Oldfield, A., \& Flower, C. (2008). Music therapy with children and their families. London and Philadelphia: Jessica Kingsley Publishers.

Papousek, M. (1996). Intuitive parenting: a hidden source of musical stimulation in infancy. In I. Deliege \& J. Sloboda (eds.), Musical beginnings: origins and development of musical competence (pp. 88-112). Oxford: Oxford University Press.

Pelham, G., \& Stacey, J. (1999). Counselling skills for creative arts therapists. Bodmin: Worth Publishing.

Poslawsky, I. E., Naber, F. B., Bakermans-Kranenburg, M. J., van Daalen, E., van Engeland, H., \& van ljzendoorn, M. H. (2015). Video-feedback intervention to promote positive parenting adapted to autism (VIPP-AUTI): a randomized controlled trial. Autism, 19, 588-603. doi: 10.1177/1362361314537124

Rogers, C. (1951). Client-centered therapy: its current practice, implications and theory. London: Constable.

Rogers, C. (1961). On becoming a person: a therapist's view of psychotherapy. London: Constable.
Benefits of video feedback in parent counselling 
Schieve, L. A., Blumberg, S. J., Rice, C., Visser, S. N., \& Boyle, C. (2007). The relationship between autism and parenting stress. Pediatrics, 119, 114-121. doi: 10.1542/peds.2006-2089Q

Schwartzberg, E. T., \& Silverman, M. J. (2016). Parent perceptions of music therapy in an on-campus clinic for children with autism spectrum disorder. Musicae Scientiae. doi: 10.1177/1029864916644420

Thompson, G., McFerran, K., \& Gold, C. (2014). Family-centred music therapy to promote social Laura K. Blauth engagement in young children with autism spectrum disorder: a randomized controlled study. Child: Care, Health and Development, 40, 840-852. doi: $10.1111 /$ cch. 12121 